\title{
VAN CONFERENTIE NAAR DE PUBLIEKE SECTOR... PLEIDOOI VOOR HET VERLEGGEN VAN DE FOCUS VAN DE TOLKTRAINING IN COMBINATIES VAN KLEINERE TALEN
}

\begin{abstract}
A bstract. Het artikel wijst op een steeds intensiever interesse van de tolkwetenschap sinds de eerste conferentie van de Critical Link in 1995 voor het tolken en vertalen in de publieke sector (Public Service Interpreting and Translation, PSIT), in Belgie afgebakend als sociaal tolken. De verlegging van de focus van conferentietolken naar PSIT was een reactie op de noodzaak voor integratie van migranten en hun participatie aan de samenleving. Dit artikel is een pledooi voor het implementeren van PSIT in de tolktraining van studenten van minder verspreide talen, dus ook de studenten Neerlandistiek. Na afbakening van basisbegrippen en een omschrijving van de situatie van PSIT in Centraal-Europa wordt het project PACI voorgesteld, dat inspiratie biedt voor de herziening of aanvulling van de klassieke curricula van de neerlandistiek extra muros (NEM) met een aanvullend opleidingstraject voor PSIT.
\end{abstract}

Trefwoorden: sociaal tolken; public service interpreting; community interpreting; tolktraining.

\section{WAAROM DIT PLEIDOOI}

Door de internationalisering en het gebruik van het Engels als algemene communicatietaal op internationale fora werd de behoefte aan conferentietolken

Doc. Mgr. Marketa ŠTefKovÁ, Ph.D., is geassocieerd hoogleraar vertaalwetenschap bij de leerstoel voor germanistiek, neerlandistiek en scandinavistiek van de Faculteit Geesteswetenschappen van de Comenius Universiteit in Bratislava. Zij specialiseert zich in de rechtsterminologie en hiermee verbonden vertaalproblematiek; correspondentieadres: Katedra germanistiky, nederlandistiky a škandinavistiky FiF, Univerzita Komenského, Gondova 2, 81499 Bratislava, Slowakije; e-mail: marketa.stefkova@uniba.sk; ORCID: https://orcid.org/0000-0001-8641-2492.

Mgr. Michal Homola is promovendus bij de leerstoel voor germanistiek, neerlandistiek en scandinavistiek van de Faculteit Geesteswetenschappen van de Comenius Universiteit in Bratislava. Hij specialiseert zich in vertaalproblematiek; correspondentieadres: Katedra germanistiky, nederlandistiky a škandinavistiky FiF, Univerzita Komenského, Gondova 2, 81499 Bratislava, Slowakije; e-mail: homola28@uniba.sk; ORCID: https://orcid.org/0000-0002-1918-9646. 
in combinaties van minder verspreide talen, waaronder ook het Nederlands, erg gering. Daartegenover opende zich door het intensief verkeer van personen en diensten, intensieve arbeids- en vluchtelingenmigratie een nieuwe sector voor de tolken in deze talencombinaties, namelijk op het gebied van integratie en inburgering. Bovendien heeft de migratiecrisis heeft in de afgelopen jaren nog nadrukkelijker gewezen op de noodzaak aan bevoegde sociaal tolken in een breed spectrum van talencombinaties.

Tolken in de publieke sector blijken ook in de tijd van de snelle ontwikkeling van de taal- en vertaaltechnologie nog steeds het meest betrouwbare en functionerende communicatieinstrument te zijn. Getrainde tolken zijn in staat de grote waaier aan aspecten erbij te betrekken, die voor een functionerende communicatie in de vele domeinen van PSIT (Public Service Interpreting and Translation) te voorschijn komen. Tot de vaakst genoemde domeinen in de vakliteratuur over PSIT $^{1}$ komen we deze domeinen tegen: recht, politie, asiel-procedure, onderwijs, sociale zaken, gezondheidszorg. Sommige landen die geconfronteerd worden met de vluchtelingencrisis en in het verleden geconfronteerd werden met grote golven arbeidsmigranten, reageren flexibel op de actuele situatie in de maatschapij ook op het gebied van de tolktraining. Voorbeelden op dit gebied zijn onder andere België met goed geinstitutionaliseerde diensten op het gebied van PSIT ondergebracht onder het zogenaamde sociaal tolken, Oostenrijk met uitgebreide trainingen voor het tolken in asielprocedures of Spanje met gespecialiseerde universitaire opleidingen gericht op PSIT. ${ }^{2}$

In dit artikel wijzen we na afbakening van een aantal basisbegrippen van PSIT op de noodzaak van het verleggen van de focus van tolkopleidingen in combinaties van minder verspreide talen, zoals die veel ook in de opleidingen Neerlandistiek in Centraal Europa voorkomen, ${ }^{3}$ tot een intensieve training van vaardigheden binnen het sociaal en gerechtstolken met het oog op hun maatschappelijke relevantie en verantwoordelijkheid tegenover de samenleving. Aansluitend stellen we een initiatief van drie vakgroepen neerlandistiek extra muros en de VUB, die inspiratie biedt voor de herziening of aanvulling van de klassieke NEM-curricula op dit gebied.

\footnotetext{
${ }^{1}$ Zie bijv. Vargas-Urpi.

${ }^{2}$ Zie meer in Štefková, Kerremans \& Bossaert.

${ }^{3}$ Hierbij wordt de combinatie Nederlands en moedertaal van studenten neerlandistiek bedoeld, zoals bijv. Nederlands en Slowaaks, Tsjechisch, Hongaars, Sloweens, Roemeens, Bulgaars, Servisch...
} 


\section{PSIT - NIEUWE FOCUS \\ BINNEN DE TOLKWETENSCHAP}

Hoewel het tolken en vertalen in de publieke sector of Public Service Interpreting and Translation (PSIT) sinds het ontstaan van de eerste onafhankelijke staatsstructuren altijd al een noodzakelijke dienst was, groeide de interesse van vertaal- en tolkwetenschappers in deze sector pas in de laatste decenia. De eerste wetenschappelijke analyses van het proces van PSIT gaan terug tot de jaren ' 60 en ' 70 . In die periode werden vooral in de VS enkele artikelen gepubliceerd die het nut van professionalisering van vertalers en tolken benadrukten, voornamelijk binnen de gezondheidszorg. In die periode werden vooral bij het verlenen van tolkdiensten meestal ad hoc tolken ingeschakeld, zonder een professioneel statuut of specifieke opleiding. Gelijksoortige initiatieven werden later (in de jaren '80) ook binnen de instellingen van het rechtssysteem in de VS en in Australië gelanceerd. In beide gevallen ging het alleen om individuele onderzoeksprojecten die helemaal niet gecoördineerd werden. De deskundigen hebben in deze onderzoeksprojecten voornamelijk op grote risico's gewezen die met het gebruik van ongetrainde tolken in de publieke sector samenhangen (VargasUrpi 52-55).

In deze periode werd het begrip community interpreting uitsluitend begrepen als aanvulling op en in tegenstelling tot de reeds vaak gebruikte term conference interpreting. Het werd toen beschouwd als het tolken dat onder leden van bepaalde minderheden werd gerealiseerd (Chesher 36). Kortom, de afbakening van dit begrip vloeide voort uit de trend van systematisering van de vertaal- en tolkwetenschap en uit de behoefte aan een overkoepelende subdiscipline die het reeds bestaande conferentietolken zou aanvullen.

Over een systematische belangstelling voor dit gebied kunnen wij echter pas in de jaren 'spreken. Een doorbraak in de boven beschreven situatie vond pas plaats met de eerste Critical Linkconferentie in het jaar 1995 in de Canadese stad Orillia. Dit was de eerste internationale conferentie die zich uitsluitend met PSIT bezighield. Het was ook de eerste keer dat het gebied van community interpreting als een zelfstandige en aparte subdiscipline van vertaal- en tolkwetenschap werd onderscheiden (Hertog \& Van der Veen 11). ${ }^{4}$

\footnotetext{
${ }^{4}$ Deze conferentie werd door het netwerk Critical Link georganiseerd, dat in 1992 aan de Universiteit van Ottawa werd opgericht. Critical Link International kunnen wij tegenwoordig als een van de belangrijkste internationale netwerken beschouwen die deskundigen op het gebied van
} 
In Europa hebben bij de professionalisering van PSIT vooral twee initiatieven een belangrijke rol gespeeld. Ten eerste was dat de oprichting van een netwerk van tolken en vertalers in de publieke sector (ENPSIT), waarin behalve professionele vertalers en tolken ook academici worden verenigd, maar ook vertegenwoordigers van publieke instellingen en van overheden. Deze organisatie werd in 2013 in België opgericht en de belangrijkste taak ervan is het creëren en controleren van internationale standaarden voor het verlenen van vertaal- en tolkdiensten binnen de publieke sector. ${ }^{5}$ Het tweede initiatief was ongetwijfeld de internationale norm ISO 13611:2014, waardoor de basisprincipes en aanbevelingen voor het uitoefenen van het beroep van PSIT worden bepaald. Deze norm bevat ook een opsomming van de belangrijkste rechten en plichten van de personen en instellingen die vertaalen tolkdiensten verlenen en van hen die ervan gebruik maken.

Al deze intiatieven waren het gevolg van de groeiende behoefte aan vertaal-en vooral tolkdiensten in combinaties van minder verspreide talen in de publieke sector. Aan de andere kant zien we de steeds groeiende dominantie van het Engels in de wereld van de wetenschappelijke en diplomatieke conferenties, waardoor het vaak niet meer nodig is om naar de talen van alle deelnemers te tolken. Naast voornoemde factoren is een van de belangrijkste redenen voor de versterking van de positie van PSIT ook de dynamische groei van globale migratie.

\section{AFBAKENING VAN PSIT}

Het begrip Public Service Interpreting and Translation (PSIT) sluit aan bij de oorspronkelijk vaak gebruikte term Community interpreting and translation. Terwijl de oorspronkelijke term vooral verwees naar het tolken binnen een minderheidsgemeenschap, kunnen wij bij de term PSIT over een uitbreiding van de focus spreken. Het sleutelwoord gemeenschap of community werd door publieke sector vervangen. De hoofdfunctie van PSIT bestaat erin om de communicatie te bemiddelen tussen publieke instellingen en personen die de officiële taal van de staat of het taalgebied niet voldoende beheersen. Het kan om etnische minderheden of migranten gaan, maar ook om gewone toeristen of personen met een ernstige, voornamelijk auditieve

PSIT verenigt. De CLI-conferenties worden sinds 1995 om de drie jaar georganiseerd en vormen een belangrijk platform voor het volgen van de laatste trends in het onderzoek van PSIT.

${ }^{5}$ Zie meer over de situatie van PSIT in België bijv. Bossaert 130-132. 
beperking. Het spectrum van publieke instellingen, in het kader waarvan het tolken en vertalen gerealiseerd kan worden, is heel breed. Hieronder vallen onder andere alle justitieorganen, zorg-, opleidings- en overheidsinstellingen.

Over het algemeen kunnen we PSIT als een relatief heterogeen onderzoeksterrein beschouwen. Daarom is het ook moeilijk om het tolken en vertalen in de publieke sector eenduidig af te bakenen. We kunnen in ieder geval ten minste twee basiskenmerken ervan vermelden die in dit verband als immanent kunnen worden beschouwd. Het eerste kenmerk is intrasocialiteit. Het PSIT wordt binnen een bepaald maatschappelijk systeem gerealiseerd (binnen de publieke sector van een concrete staat) en wordt door de wetgeving, maar ook door conventies van het systeem geregeld. Het tweede kenmerk betreft de assymetrische relatie tussen de twee partijen in de communicatie. Aan de ene kant van de communicatieve situatie staat een vertegenwoordiger van een publieke instelling (arts, rechter, ambtenaar) en aan de andere kant een anderstalige persoon (lid van een ethnische minderheid, vluchteling, economische of arbeidsmigrant enz.). Er bestaan meerdere factoren die de assymetrie tussen deze communicatiepartners stimuleren, waaronder de positie van een expert en de leek in het gegeven domein, de maatschappelijke status, maar vooral de confrontatie van de meerderheids/ minderheids- cultuur en taal.

De oorspronkelijke trend bestond erin om op het onderzoek van community interpreting dezelfde criteria en werkwijzen toe te passen als op het conferentietolken. Vandaag kunnen wij echter constateren dat er een relatief groot verschil tussen deze twee gebieden bestaat, vooral qua toegepaste onderzoeksmethoden. Op het terrein van conferentietolken wordt meer aandacht besteed aan verschillende cognitieve, neurolinguïstische en neurofysiologische aspecten (het geheugen of anticipatievermogen van de tolk, maar ook op het concrete tolkproces (aantal autocorrecties, décalage enz.). In het onderzoek van PSIT wordt meer nadruk gelegd op perceptie van de rol van de tolk of vertaler en van andere deelnemers aan het vertaal- of tolkproces, op ethische aspecten, verwachtingen van de klant of professionaliteit en neutraliteit van de tolk (Jacobsen 155-156).

Volgens Rudvin (31) heeft zich het PSIT-onderzoek vanuit de oorspronkelijk prescriptieve aanpak ontwikkeld naar een meer realistische, veelomvattende aanpak. In de prescriptieve fase steunde het op dezelfde criteria als op conferentietolken werden toegepast. In latere fase wordt aandacht besteed aan de complexiteit en positie van deze diensten in de maatschappij. Vargas- 
Urpi (50) benadrukt het interdisciplinaire karakter van het onderzoek van PSIT. Tegenwoordig is het niet meer alleen het object van vertaal- en tolkwetenschap, maar wordt het in hoge mate ook door andere disciplines beïnvloed, zoals toegepaste taalkunde, sociologie, antropologie, psychologie of communicatietheorie.

Qua omvang van het uitgevoerde onderzoek gaat het vooral om twee domeinen van PSIT: gezondheidszorg en recht. Relatief veel onderzoek wordt als gevolg van de globale migratie en vluchtelingenstromen ook uitgevoerd over tolken in asielprocedures. Maar over het algemeen kunnen wij stellen dat het aantal relevante onderzoeken op het terrein van PSIT sinds de jaren ' 90 gestaag toeneemt en dat er steeds nieuwe aspecten worden benaderd.

De grootste aandacht wordt gegeven aan het domein medisch tolken. Het gaat hier om een uiterst divers en complex gebied, waardoor ook het gerelateerde onderzoek op diverse onderwerpen wordt gericht. Een verbindend aspect is echter de kwaliteit: kwaliteit van het vertaalproces, kwaliteit van de gehele prestatie, kwaliteit van de communicatie en de daarvan afhankelijke gezondheidszorg enz. (Pöchhacker 155). Een specifiek aspect van dit domein is de hoge mate van gevoeligheid en vertrouwelijkheid van de gegevens, waarmee er bij het onderzoek wordt omgegaan. Het gaat om uiterst persoonlijke gegevens van patiënten die tijdens getolkte consultaties door de arts worden vermeld. Daarom is het heel belangrijk om de toegang tot en de manipulatie met deze gegevens streng te controleren en normeren.

Het juridische discours hoort naast het medische domein tot de meest onderzochte domeinen van PSIT. Hale (90) wijst op enkele redenen, waarom juist dit domein voor de theoretici zo interessant is: enerzijds heeft dat te maken met een relatief goede toegankelijkheid van opnames en ander materiaal uit de processen of verhoren, en anderzijds gaat het natuurlijk om een gebied dat relatief veel aandacht van publiek en media trekt. De derde reden is het consistente karakter van het juridische discours wat een meer effectieve categorisatie en analyse van verzamelde gegevens mogelijk maakt (bijv. in vergelijking met het medisch domein).

Thematisch worden de onderzoeken gericht op de analyse van het specifieke discours van rechtshandelingen en politieverhoren en hun invloed op het tolkproces, verder op de rol van de tolk binnen een proces of verhoor en de eraan gerelateerde training en professionalisering van het juridisch tolken. 


\section{PSIT IN LOKALE CONTEXTEN}

In Centraal-Europa is het begrip PSIT tamelijk onbekend en de uitoefening van het sociaal tolken is nauwelijks wettelijk afgebakend en geïnstitutionaliseerd. Er bestaat wel een lange traditie in de certificering en de registratie van beëdigde tolken. Deze tolken treden in de praktijk heel vaak in de contexten van PSIT op. Het gaat hier om afgestudeerden van tolkopleidingen met een klassieke training in consecutief en simultaantolken, filologen en deskundigen in een breed spectrum van disciplines met taalkennis geconfronteerd. In de praktijk worden ze met de diverse aspecten van PSIT geconfonteerd, met name met de asymmetrische machtpositie van de deelnemers van de communicatie, de diversiteit van contexten, of de noodzaak van een combinatie van tolktechnieken en de ethische aspecten bij concrete opdrachten.

Om meer inzicht te verlenen in deze context beschrijven we - uitgaande van de eigen achtergrond - de situatie in Slowakije. Deze omschrijving plaatsen we in de bredere context van Centraal-Europa door te vergelijken met de situatie in Tsjechië en Polen. Dit inzicht motiveert de stappen in de richting van het ontwerp van een aanvullend opleidingstraject voor het sociaal tolken in het kader van het project Erasmus+ PACI, dat geïntegreerd kan worden in de NEM-opleidingen en nader omschreven wordt in punt 5.

Slowakije is een land met een lange traditie in de opleiding van tolken en vertalers. In een land met vijf miljoen inwoners bieden zes universiteiten een geformaliseerde tolkopleiding. Deze opleidingen worden aangeboden in een breed spectrum van talen in combinatie met het Slowaaks. Het curriculum is erg traditioneel opgebouwd en wordt ingedeeld in literair en vakvertalen, simultaan en consecutief tolken. De studenten worden nauwelijks in het PSIT getraind, hoewel het veldonderzoek aantoont dat het aantal opdrachten in conferentietolken in de laatste tien jaar beduidend is gedaald (zie Djovčoš \& Šveda, Mýty a fakty 147 en Didaktika 132).

Een van de redenen is de tamelijk beperkte mogelijkheid van specialisatie binnen de opleiding door de verplichte verbinding van het tolken en het vertalen. Een andere reden is dat de opleiding door een gecompliceerde accreditatieprocedure niet voldoende vrijheid heeft om flexibel op de ontwikkelingen in de samenleving in te spelen. Zo ontstaat er een kloof tussen de opleiding en de praktijk van PSIT.

Tot op heden bestaat er een mythe in de theorie en didactiek van het tolken in Slowakije, dat community of public service interpreting enkel be- 
trekking heeft op het tolken voor migranten. Deze beperkte opvatting van het vak leidde tot de redenering dat het in Slowakije niet nodig is om een gespecialiseerde training of opleiding in PSIT aan te bieden, omdat migratie in Slowakije geen zwaarwegend probleem is (Tužinská, "Communication" 52).

Afgezien van de officieel erkende minderheden die in Slowakije overwegend leven als gevolg van politieke beslissingen rond de verlegging van grenzen en het uiteenvallen van Oostenrijk-Hongarije in 1918, hebben er in Slowakije geen grote migratiegolven plaatsgevonden. De opvallendste groepen na de Tweede Wereldoorlog zijn de nu al ingeburgerde Vietnamese en Chinese gemeenschappen. Die werden als burgers van verbroederde landen uitgenodigd voor universitaire studies tijdens het socialistisch regime (www1). Het feit dat het verlenen van vertaaldiensten aan deze twee taalgroepen onderontwikkeld was en is, toont onder andere het feit dat voor deze talen slechts vijf gecertificeerde tolken bij het ministerie van Justitie geregistreerd staan.

Sinds de toetreding van Slowakije tot de EU in 2004 is het aantal arbeidsmigranten uit EU-lidstaten exponentieel toegenomen. Bratislava is dankzij zijn gunstige ligging tussen Wenen en Boedapest een magneet geworden voor multinationals en veel buitenlandse bedrijven. De sterke ontwikkeling van de automobielindustrie zorgt voor een intensieve arbeidsmigratie van werknemers buiten de grenzen van de EU, voornamelijk uit Servië en Oekraïne, zelfs Zuid-Korea (www1).

Slowakije heeft echter nog geen geïnstitutionaliseerd en functionerend model van sociaal tolken en vertalen ontwikkeld dat deze groepen migranten kan helpen bij hun integratie in de samenleving. Het is belangrijk te benadrukken dat deze gemeenschappen alleen het recht hebben om hun taal te gebruiken in strafprocedures en in het geval van vluchtelingen in de asielprocedure, omdat hun talen geen erkende minderheidstalen zijn op het grondgebied van de Slowaakse republiek (Tužinská, Medzi riadkami 78). Aan deze groepen worden er dus geen vertaaldiensten verleend in scholen, ziekenhuizen en andere maatschappelijke domeinen door de overheid.

Beëdigde vertalers en tolken verrichten in de Slowaakse context vertaalen tolkdiensten in opdracht van politie, het openbaar ministerie en rechtbanken /gerechtshoven. Zij dekken dus slechts een klein deel van alle opdrachten die onder de publieke sector vallen. De minimumeisen voor de opleiding en andere persoonlijke criteria van de tolken en vertalers, de wijze van certificering en de sancties in geval van overtreding van de verplichtingen en ook de vergoeding zijn in de Wet betreffende deskundigen tolken en vertalers 
verankerd. ${ }^{6}$ Deze geeft precieze details over de identificatiesymbolen van beëdigde tolken en vertalers, zoals een officieel stempel en een identificatiebewijs, en schetst de formele lay-out van de vertaling. De wet voorziet ook in een aantal ethische aspecten, zoals vertrouwelijkheid en mogelijke redenen om een bepaalde opdracht te weigeren. Op andere domeinen van de publieke sector staat de professionalisering en institutionalisering van de tolken vertaaldiensten nog in kinderschoenen.

De situatie in Tsjechië en in Polen is gedeeltelijk met de Slowaakse vergelijkbaar. Ook in Tsjechië en in Polen worden de gerechtstolken door het Ministerie van Justitie geëxamineerd en geregistreerd. Het verlenen van vertaal- en tolkdiensten in andere contexten van de publieke sector wordt echter door de wetgeving niet afgebakend. Afzonderlijke voorschriften bestaan er verder nog voor de juridische en asielprocedures. De eerste initiatieven op het gebied van de professionalisering van PSIT in alle drie landen vinden plaats op het niveau van de NGO's, die zich voor rechten van minderheiden, migranten en vluchtelingen inzetten. ${ }^{7}$

In Tsjechië werd een belangrijke stap naar de professionalisering van PSIT gemaakt door het opstellen van een gedragscode voor sociaal tolken. Door deze gedragscode worden niet alleen de rol en de plichten van de tolk binnen de publieke sector vastgelegd, maar ook de voorwaarden, op basis waarvan gebruik gemaakt kan worden van de diensten van een professionele tolk. Enkele projecten van het Instituut van Vertalers en Tolken in Praag richten zich op de opleiding van niet geschoolde tolken voor PSIT. De Palacký Universiteit in Olomouc biedt zelfs een apparte masteropleiding in PSIT aan, echter alleen in de talencombinatie Tsjechisch-Engels.

In Polen wordt de tolkopleiding traditioneel aangeboden in de combinatie van het Pools met grote talen. In Warschau wordt er ook een gespecialiseerde training in het medisch tolken aangeboden. Helaas blijven de kleine en exotische talen net als in de andere omschreven landen buiten beschouwing. ${ }^{8}$ (Štefková, Kerremans \& Bossaert).

\footnotetext{
${ }^{6}$ De activiteiten van tolken en vertalers in Slowakije zijn geregeld bij wet nr. 308/2007 Z.z. en de uitvoeringsbepalingen daarvan, gewijzigd bij wet nr. 65/2018, decreet nr. 490/2004 Z.z. tot regeling van de uitvoering van de wet. nr. 382/2004 Z.z. over getuigen, tolken en vertalers en over de wijziging van bepaalde wetten en decreet nr. 491/2004 Z.z. over de bezoldiging, de vergoeding van de kosten en de vergoeding van de bestede tijd van getuigen, tolken en vertalers.

${ }^{7}$ Deze initiatieven worden ondersteund onder andere door UNHCR en IOM, maar hebben helaas geen systematisch en duurzaam karakter.

${ }^{8}$ Meer informatie over de stand van PSTI in Slowakije, Tsjechie en Polen zie in Štefková, Kerremans \& Bossaert.
} 
Het voorbeeld van Centraal-Europa toont hoe divers de noden aan sociaal tolken en vertalen in de samenleving kunnen zijn, en wijst er tegelijkertijd op dat de bestaande tolkopleidingen geen adequaat antwoord geven op actuele ontwikkelingen en uiteindelijk een slechts heel beperkte opleiding aan tolken in kleine talencombinaties bieden. Dat betekent dat er alternatieve opleidingsvormen nodig zijn voor bepaalde talencombinaties en domeinen van PSIT. Deze opleidingen dienen op een grondige analyse van de maatschappelijke navraag te berusten.

Het Nederlands valt in de regio van Centraal-Europa onder de weinig verspreide talen. Hoewel de economische en culturele contacten van CentraalEuropese landen met de Lage Landen erg intensief zijn en het aantal Nederlandstalige expats in Centraal-Europa tamelijk hoog is, zijn er op de markt maar weinig bevoegde vertalers en tolken ter beschikking die in staat zijn om adequaat vertaal- en tolkendiensten in de publieke sector te verlenen. Meestal gaat het om mensen die hun tolk- en vertaalcompetentie zelf hebben ontwikkeld bij het uitvoeren van opdrachten in de praktijk. Learning by doing betekent hier niet het trainen aan de hand van voorbeelden uit de praktijk, maar het leren van fouten en mislukte vertaal- en tolkopdrachten in de praktijk met meer of minder zware gevolgen voor de opdrachtgever of de ontvanger van deze diensten.

$\mathrm{Er}$ is ons voorzover geen gespecialiseerde opleiding bekend die binnen de Europese Unie of elders training voor tolken en vertalers in de publieke sector voor het Nederlands aanbiedt, behalve het uitstekende opleidingstraject van sociaal tolken en vertalen, dat aangeboden worden door Vlaamse overheidsdiensten, die echter toegespitst worden op sectoren en noden van de Belgische (Vlaamse) context. Door het beperkte aantal beroepsbeoefenaars van het vak bestaat er ook geen systematische professionalisering. Volgens onze steekproefsgewijze verworven inzichten in de beroepspraktijk van PSIT met de talencombinatie Nederlands, is er onder deze tolken en vertalers ook weinig kennis van de vertaaltechnologie waardoor die ook zelden gebruikt wordt.

\section{HET EERSTE INITIATIEF BINNEN \\ DE NEERLANDISTIEK EXTRA MUROS - HET PACI-PROJECT}

De onder punt 4 genoemde vaststellingen waren de eerste impuls voor het opstarten van een internationaal project gericht op de ontwikkeling van een strategisch partnerschap tussen onderwijsinstellingen neerlandistiek extra 
muros voor de professionalisering van het tolken en vertalen in de publieke sector in het Nederlands. Het project Erasmus+ PACI (Professional and Accessible Community Interpreting $)^{9}$ wordt uitgevoerd door drie afdelingen neerlandistiek in Centraal Europa - Bratislava, Olomouc en Wrocław samen met de Vrije Universiteit Brussel, een partner uit de Lage Landen.

Het doel van dit project was het een opleidingstraject voor het tolken en vertalen in de publieke sector voor het Nederlands te ontwikkelen. Dit opleidingstraject werd als een pilot toegepast binnen de opleidingen neerlandistiek extra muros om studenten neerlandistiek te motiveren zich meer in deze subdomeinen van de tolk- en vertaalwetenschap te verdiepen. Het werd in de eerste fase gericht op combinaties van talen van de partners (Slowaaks, Tsjechisch, Pools) en het Nederlands en wordt na aanpassingen ook aangeboden in andere taalcombinaties.

We zijn ervan overtuigd dat de studenten neerlandistiek uitstekende kandidaten zijn voor het overnemen van de taak van professionele tolken en vertalers in de publieke sector. Zij beschikken namelijk naast een uitstekende kennis van het Nederlands ook over een basiscompetentie in vertalen en tolken. Die ontwikkelen ze in het kader van keuzevakken gericht op tolken en vertalen. Daarnaast zijn ze in staat om hun kennis van het plaatselijke systeem van overheidsinstellingen, terminologie en jargon van de relevante domeinen, regelgeving en wetgeving op het gebied van PSIT in hun land aan te vullen.

Het traject, ontwikkeld binnen het project, combineert vier e-learningmodules met een intensieve vertaal en tolkentraining tijdens een trainingsweek. Naast de praktische kennis van vertaalstrategieën en vertaalprocedures wordt in de e-learningmodules de nadruk gelegd op het gebruik van de relevante terminologie en vertaaltools, en de praktische en ethische aspecten van de uitoefening van het beroep van sociaal tolk en vertaler.

Het eerste proeftraject van het project liep in het academiejaar 2019/20 met dertig kandidaten in Brussel, Bratislava, Olomouc en Wrocław. Na het succesvol afronden van het project zijn we van plan om de opleiding ook aan andere universiteiten in onze regio aan te bieden. De NEM-opleidingen zijn met behulp van een handboek voor de toepassing van het opleidingstraject in staat om de cursussen volledig of gedeeltelijk te integreren in hun opleiding.

\footnotetext{
${ }^{9}$ Erasmus + project PACI, projectnummer 2017-1-SK01-KA203-035412, https://www.kgns. info/paci, geraadpleegd op 20.03.2021.
} 


\section{CONCLUSIE}

De belangstelling van de overheidsinstellingen voor de verlening van het sociaal tolken, de kwaliteit van de opleiding en de mate van institutionalisering hangen nauw samen met het belang van de overheid en de samenleving met betrekking tot een effectieve integratie en inclusie van de doelgroepen van PSIT. Het is duidelijk dat een systematische aanpak, waarbij ervaring, kennis, ethische beginselen en praktische benaderingen internationaal worden gedeeld, een belangrijke bijdrage kan leveren aan alle betrokken landen. Professionalisering en institutionalisering van PSIT kan tevens bijdragen tot de erkenning van het belang van deze diensten. Samenwerking van de overheid, NGO's en onderwijsinstellingen is hierbij een voorwaarde voor de invoering van doeltreffende modellen voor het sociaal tolken en vertalen met het oog op kwaliteit, solidariteit en bescherming van de mensenrechten.

Het artikel biedt impulsen tot verder nadenken over de implementatie van dit onderwerp in de curricula Neerlandistiek extra muros. Op die manier kunnen Nederlandstaligen in Centraal-Europa in de toekomst beroep doen op vertaal- en tolkendiensten in sectoren waar het communiceren via de lingua franca niet volstaat. Projecten als PACI kunnen een aanzet geven in de richting van professionalisering op dit gebied.

\section{BIBLIOGRAFIE}

Bossaert, Benjamin. "Institucionalizace a profesionalizace komunitního tlumočení ve Vlámsku." Komunitni tlumočeni v České republice a v nizozemsky hovořcich zemich, onder redactie van Pavlína Knap-Dlouhá e. a. Univerzita Palackého v Olomouci, 2020, pp. 130-132.

Chesher, Tery. Rhetoric and reality. Two decades of community interpreting and translating in Australia, 1997. Beschikbaar op https://doi.org/10.1075/btl.19.29che. Geraadpleegd op 20.03.2021.

Crossing Borders in Community Interpreting: Definitions and dilemmas, onder redactie van C. Valero-Garcés en A. Martin. John Benjamin's.

Djovčos, Martin, en Pavol Šveda, editors. Didaktika prekladu a tlmočenia na Slovensku. Bratislava: Veda, 2018.

Djovčoš, Martin, en Pavol Šveda. Mýty a fakty o preklade a tlmočení na Slovensku. Bratislava: Veda, 2017.

Hale, Sandra Beatriz. Community Interpreting. Palgrave Macmillan, 2007.

Hertog, Erik, en Bart van der Veen. "Taking Stock: Research and Methodology in Community Interpreting”. Linguistica Antverpiensia. New Series, nr. 5, 2006, pp. 11-17. 
Jacobsen, Benthe. "The community interpreter: a question of role." Hermes - Journal of language and communication studies, nr. 42, 2009, pp. 155-166.

Pöchhacker, Franz. "Research and Methodology in Healthcare Interpreting." Linguistica Antverpiensia: New Series, nr. 5, 2006, pp. 135-159.

Rudvin, Mette. "The Cultural Turn in Community Interpreting: A Brief Analysis of Epistemological Developments in Community Interpreting Literature in the Light of Paradigm Changes in the Humanities." Linguistica Antverpiensia: New Series, nr. 5, pp. 21-41.

Štefková, Marketa, Koen Kerremans en Benjamin Bossaert. Learning from good examples. Professionalisation of community interpreting in Central Europe. Univerzitné vydavatel'stvo UK, 2020 (online beschikbaar: www.kgns.info/intellectual-outputs. Geraadpleegd op 20.05.2021)

Tužinská, Helena. "Communication In The Asylum Courts. Limits od Inquiry.” Slovenský Národopis, vol. 57, nr. 5, 2009, pp. 560-578.

Tužinská, Helena. Questions of Description and Translation: Using Data from Anthropology and Ethnology in the Conduct and Interpretation of Interviews with Immigrants. Stimul, 2010 (online beschikbaar: www.old.hrl.sk/publikacie. Geraadpleegd op 20. 03.2021).

Tužinská, Helena. Medzi riadkami. Bratislava: ArtForum, 2019.

Vargas Urpi, M. "State of the art in community interpreting research: mapping the main research topics." Babel, vol. 58, nr. 1, 2012, pp. 50-72.

www1: iom.sk/en/migration/migration-in-slovakia.html. Geraadpleegd op 20.03.2021.

\section{OD KONFERENCJI DO SEKTORA PUBLICZNEGO... \\ APEL O PRZENIESIENIE UWAGI W SZKOLENIACH TŁUMACZY JEZZYKÓW NISZOWYCH Z TŁUMACZENIA KONFERENCYJNEGO NA TŁUMACZENIA USTNE W SEKTORZE PUBLICZNYM (PSIT)}

\section{Streszczenie}

Od czasu pierwszej konferencji Critical Link w 1995 r. datuje się wzrost zainteresowania tłumaczeniami ustnymi w zakresie tłumaczeń ustnych i pisemnych $\mathrm{w}$ sektorze publicznym (Public Service Interpreting and Translation, PSIT), określanymi w Belgii jako tłumaczenia społeczne. Przeniesienie uwagi z thumaczeń konferencyjnych na PSIT było odpowiedzią na potrzebę integracji migrantów i ich udziału w społeczeństwie. Niniejszy artykuł jest apelem o wdrożenie tłumaczeń ustnych w sektorze publicznym (PSIT) do kształcenia tłumaczy studentów rzadziej używanych języków, w tym studentów filologii niderlandzkiej. Po zdefiniowaniu podstawowych pojęć i opisie sytuacji PSIT w Europie Srodkowej zaproponowano projekt PACI, który jest inspiracją do rewizji lub uzupełnienia klasycznych programów nauczania filologii niderlandzkich extra muros (NEM) o dodatkową ścieżkę szkoleniową dla thumaczeń ustnych w sektorze publicznym (PSIT).

$$
\text { Przełożyła Beata Popławska }
$$

Slowa kluczowe: thumaczenia społeczne; thumaczenia ustne w sektorze publicznym (PSIT); języki niszowe; szkolenia w zakresie tłumaczeń ustnych. 


\section{FROM CONFERENCE TO COMMUNITY... A PLEA FOR SHIFTING THE FOCUS OF INTERPRETER TRAINING IN SMALL LANGUAGE COMBINATIONS FROM CONFERENCE INTERPRETING TO INTERPRETING IN THE PUBLIC SECTOR}

\section{S u m m a ry}

This article illustrates the increasing interest in interpreting since the first Critical Link conference in 1995 which focused on the discipline of Public Service Interpreting and Translation (PSIT), which is defined in Belgium as social interpreting. The shift in focus from conference interpreting to PSIT was a response to the need to integrate migrants and to support their participation in society. This article is a plea for the implementation of PSIT in the interpreting training of students of languages of lesser diffusion, including students of Dutch. After delineating the basic concepts of PSIT and describing the situation of PSIT in Central Europe, the PACI project, which provides inspiration for revising or supplementing the classical curricula of extramural Dutch Studies, with an additional training path for PSIT, is then presented.

Keywords: community interpreting; public service interpreting; languages of lesser diffusion; interpreter training. 